Jurnal Sains Riset (JSR)

ISSN 2088-0952

\title{
ANALISIS RASIO C/N KOMPOS LIMBAH KULIT UBI AKIBAT PENGECILAN UKURAN BAHAN DAN LAMA FERMENTASI
}

\author{
Cut Mulia Sari ${ }^{(1)}$, Karnilawati ${ }^{(2)}$, Rudi Fadhli ${ }^{(3)}$ \\ ${ }^{1,2 \& 3}$ Jurusan Agroteknologi Fakultas Pertanian Universitas Jabal Ghafur, Sigli \\ Email: cutmuliasari@gmail.com
}

\begin{abstract}
ABSTRAK
Kulit ubi merupakan limbah dari pengolahan keripik, kerupuk, tape dan olahan ubi lainnya yang dibuang begitu saja tanpa dimanfaatkan. Salah satu inovasinya adalah dengan memanfaatkan kulit ubi tersebut menjadi kompos. Kompos dengan kualitas yang baik tentunya memberikan hasil bagi tanaman yang baik pula. Hal ini sangat tergantung pada bahan baku dan perlakuan pada saat pembuatan kompos. Pengecilan ukuran dan lamanya fermentasi menjadi faktor penting dalam penentuan kualitas kompos kulit ubi. penelitian ini bertujuan untuk mengetahui rasio $\mathrm{C} / \mathrm{N}$ kompos kulit ubi akibat faktor pengecilan ukuran bahan baku dan lamanya fermentasi yang tepat dalam menghasilkan kompos kulit ubi. Penelitian dilaksanakan di Ruang Fermentasi Fakultas Pertanian Universitas Jabal Ghafur Glee Gapui Sigli mulai April sampai September 2019. Penelitian ini menggunakan Rancangan Acak Lengkap (RAL) pola faktorial 2x2 dengan 3 ulangan. Faktor pertama pengecilan ukuran bahan terdiri dari 2 taraf yaitu pencacah manual dan penggilingan. Faktor kedua lama fermentasi terdiri dari 2 taraf yaitu 4 minggu dan 8 minggu. Hasil Penelitian menunjukkan bahwa pengecilan ukuran bahan berpengaruh tidak nyata terhadap $\mathrm{C}$ organik dan rasio $\mathrm{C} / \mathrm{N}$. Perlakuan lama fermentasi berpengaruh sangat nyata terhadap $\mathrm{N}$ total dan $\mathrm{C} / \mathrm{N}$, berpengaruh tidak nyata terhadap $\mathrm{C}$ organik. Ada hubungan yang signifikan dari peran $\mathrm{N}$ total dalam proses rasio $\mathrm{C} / \mathrm{N}$ terhadap lamanya fementasi dan terdapat pengaruh yang sangat nyata dari lama fermentasi terhadap $\mathrm{N}$ total dan rasio $\mathrm{C} / \mathrm{N}$.
\end{abstract}

Kata Kunci : Kompos, fermentasi, rasio C/N

\section{PENDAHULUAN}

Kulit ubi merupakan limbah dari pengolahan keripik, kerupuk, tape dan olahan ubi lainnya yang dibuang begitu saja tanpa dimanfaatkan. Seiring dengan meningkatnya konsumsi olahan ubi maka semakin meningkat pula jumlah limbahnya. Limbah kulit ubi yang dibiarkan begitu saja dapat menimbulkan banyak masalah terhadap lingkungan dan kesehatan, karena limbah ini sangat sulit terurai dan menimbulkan bau. Di Aceh limbah kulit ubi sangat berlimpah dan hanya dimanfaatkan untuk pakan ternak saja. Sebenarnya kulit ubi dapat diolah menjadi pupuk organik karena kulit ubi merupakan bahan organik dan mengandung unsur yang dapat dimanfaatkan oleh tanaman. Untuk mendapatkan unsur tersebut, maka kulit ubi harus diurai terlebih dahulu agar tanaman dapat menyerap unsur hara yang tersedia. Oleh sebab itu salah satu inovasinya adalah dengan memanfaatkan kulit ubi tersebut menjadi kompos. Kompos dengan kualitas yang baik tentunya memberikan hasil bagi tanaman yang baik pula. Hal ini sangat tergantung pada bahan baku dan perlakuan pada saat pembuatan kompos. Pengecilan ukuran dan lamanya fermentasi menjadi faktor penting dalam penentuan kualitas kompos kulit ubi.

Kulit ubi kayu baru dimanfaatkan oleh sebagian masyarakat untuk pakan ternak. Padahal kulit ubi kayu memiliki kandungan karbon $59,31 \%$, hydrogen $9,78 \%$, nitrogen 
$2,06 \%$, sulfur $0,11 \%$ dan air $11,4 \%$ sebagai unsur yang dibutuhkan untuk pertumbuhan tanaman. Kompos kulit ubi kayu bermanfaat sebagai sumber nutrisi dan insektisida bagi tanaman (Ankabi, 2007 ).

Penelitian ini bertujuan untuk mengetahui rasio $\mathrm{C} / \mathrm{N}$ faktor pengecilan ukuran bahan baku dan lamanya fermentasi yang tepat dalam menghasilkan kompos kulit ubi kayu

\section{METODOLOGI}

Penelitian dilaksanakan di Ruang Fermentasi Fakultas Pertanian Universitas Jabal Ghafur Glee Gapui Sigli yang dimulai April sampai September 2019.

Bahan yang digunakan dalam penelitian ini adalah kulit ubi, EM4, gula merah, dedak, air dan bahan laboratorium yang diperlukan dalam penelitian.

Alat yang digunakan dalam penelitian ini adalah plastik sampah warna hitam, termometer, hand sprayer, parang, mesin penggiling, ember dan alat-alat laboratorium lain yang diperlukan dalam menunjang penelitian.

Penelitian ini menggunakan Rancangan Acak Lengkap (RAL) pola faktorial $2 \times 2$ dengan 3 ulangan. Faktor pertama pengecilan ukuran bahan terdiri dari 2 taraf yaitu pencacah manual dan penggilingan. Faktor kedua lama fermentasi terdiri dari 2 taraf yaitu 4 minggu dan 8 minggu. Dengan demikian diperoleh 4 perlakuan dengan 3 ulangan sehingga secara keseluruhan terdapat 12 satuan percobaan.

\begin{tabular}{|c|c|c|c|}
\hline \multirow[t]{3}{*}{ Tabel } & 1. Susu & \multicolumn{2}{|c|}{ Kombinasi Perlakuan } \\
\hline & Pengeci & Ukuran & dan Lama \\
\hline & Fermen & & \\
\hline No & $\begin{array}{l}\text { Kombinasi } \\
\text { Perlakuan }\end{array}$ & $\begin{array}{l}\text { Pengecilan } \\
\text { Ukuran }\end{array}$ & $\begin{array}{c}\text { Lama } \\
\text { Fermentasi }\end{array}$ \\
\hline 1. & P1F1 & $\begin{array}{c}\text { Pencacah } \\
\text { Manual }\end{array}$ & 4 Minggu \\
\hline 2. & P1F2 & $\begin{array}{c}\text { Pencacah } \\
\text { Manual }\end{array}$ & 8 Minggu \\
\hline 3. & $\mathrm{P} 2 \mathrm{~F} 1$ & Penggilingan & 4 Minggu \\
\hline 4. & $\mathrm{P} 2 \mathrm{~F} 2$ & Penggilingan & 8 Minggu \\
\hline
\end{tabular}

Data yang diperoleh akan dianalisis secara statistik dengan menggunakan Uji T, corelattion dan ANOVA (analysis of variance) apabila hasil uji menunjukkan pengaruh nyata maka akan dilanjutkan dengan uji lanjut beda nyata terkecil (BNT).

\section{Persiapan Bahan Baku}

Persiapan bahan baku berupa pengambilan limbah kulit ubi di Saree Kecamatan Lembah Seulawah Kabupaten Aceh Besar dan dilakukan penyortiran dan pembersihan agar tidak terikut bahan lain selain kulit ubi. Kulit ubi dilakukan analisis awal sebelum pengomposan untuk mengetahui unsur $\mathrm{C}, \mathrm{N}, \mathrm{P}, \mathrm{K}$ dan rasio $\mathrm{C} / \mathrm{N}$ bahan baku. Selanjutnya kulit ubi dilakukan pengecilan ukuran sesuai dengan perlakuan yaitu dengan pencacahan manual dan penggilingan.

\section{Pembuatan Biakan EM4 (Modifikasi dari Firmansyah, 2010)}

Pembuatan biakan EM4 diawali dengan pembuatan Molase dan diikuti oleh pembiakan bakteri EM4. Pembuatan molase (air manis) membutuhkan gula merah dan air bersih. Selanjutnya air dipanaskan hingga mendidih ditambahkan dedak, molase, terasi dan diaduk rata. Setelah campuran adonan tersebut didinginkan maka ditambahkan dengan larutan EM4 dan diaduk rata.

\section{Pembuatan Kompos Kulit Ubi (Modifikasi dari Firmansyah (2010); Yuliani dan Nugraheni, 2010)}

Kulit ubi yang sudah dilakukan perlakuan pengecilan ukuran bahan baku, dimasukkan ke dalam plastik hitam, ditaburkan dengan dedak secara tipis diatasnya dan disemprotkan dengan biakan EM4 yang telah dilarutkan dalam air sampai campuran berkadar air kurang lebih $60 \%$. Selanjutnya dilakukan hal yang sama dengan membuat lapisan kedua dan seterusnya. Media bahan kompos yang telah disusun, 
ditutup dengan terpal/plastik hitam agar bila hujan turun, proses pembuatan tidak terpengaruh dan dapat terhindar dari sinar matahari secara langsung. Selain itu penutupan berfungsi menjaga suhu agar mikrobia dekomposer dapat aktif bekerja. Pada 4 hari pertama dilakukan pengecekan suhu dan apabila suhu melebihi $50{ }^{\circ} \mathrm{C}$ maka harus dilakukan pembalikan kompos, dan selanjutnya pengecekan suhu dilakukan 1 minggu sekali. Penyiraman akan dilakukan jika diperlukan. Fermentasi kompos ini dilakukan sesuai dengan perlakuan lamanya fermentasi (F) yaitu 4 minggu dan 8 minggu.

\section{Parameter Analisis}

Analisis kompos dilakukan sebanyak 2 tahap yaitu pada tahap masa fermentasi 4 minggu dan 8 minggu yaitu analisis $\mathrm{C}$ organik, N-total, rasio $\mathrm{C} / \mathrm{N}$.

\section{HASIL DAN PEMBAHASAN}

\section{Hasil Analisis Kompos Kulit Ubi Kayu}

Hasil analisis kompos kulit ubi akibat pengecilan ukuran bahan dan lama fermentasi dapat dilihat pada Tabel 2 .

Tabel 2. Hasil Analisis Kompos Kulit Ubi Kayu

\begin{tabular}{|c|c|c|c|}
\hline \multirow[b]{2}{*}{ Perlakuan } & \multicolumn{3}{|c|}{$\begin{array}{c}\text { Sifat Kimia Kompos Kulit } \\
\text { Ubi Kayu }\end{array}$} \\
\hline & $\begin{array}{c}\mathrm{C} \\
\text { organik } \\
(\%)\end{array}$ & $\begin{array}{l}\mathrm{N} \\
\text { total } \\
(\%)\end{array}$ & $\mathrm{C} / \mathrm{N}$ \\
\hline SNI Kompos & $9,8-32$ & $<6$ & $\leq 20$ \\
\hline $\begin{array}{l}\text { Pencacah Manual } \\
\text { dan Fermentasi } 4 \\
\text { minggu } \\
\text { Penggilingan dan }\end{array}$ & 33,59 & 0,51 & 66,49 \\
\hline $\begin{array}{l}\text { Fermentasi } 4 \text { minggu } \\
\text { Pencacah Manual } \\
\text { dan Fermentasi } 8\end{array}$ & 31,91 & 0,64 & 50,87 \\
\hline $\begin{array}{l}\text { minggu } \\
\text { Penggilingan dan }\end{array}$ & 34,06 & 0,47 & 72,65 \\
\hline Fermentasi 8 minggu & 35,11 & 0,65 & 54,82 \\
\hline
\end{tabular}

Sumber: Data Hasil Analisis Laboratorium, 2019

Berdasarkan Tabel 2 terlihat proses dekomposisi dari limbah kulit ubi kayu belum terjadi secara sempurna, hal ini dapat dilihat nilai dari rasio $\mathrm{C} / \mathrm{N}$ yang tinggi tidak sesuai dengan standar yang ditetapkan. Hasil rasio $\mathrm{C} / \mathrm{N}$ limbah kulit ubi kayu setelah dikomposkan berkisar antara 50,87 \%. Sebagaimana diketahui, prinsip pengomposan adalah untuk menurunkan rasio $\mathrm{C} / \mathrm{N}$ bahan organik hingga sama dengan $\mathrm{C} / \mathrm{N}$ tanah $(<20)$ (Djuarnani et al, 2005). Maka dengan nilai $\mathrm{C} / \mathrm{N}$ rasio tersebut proses dekomposisi bahan organik berjalan lambat sehingga unsur-unsur hara belum tersedia bagi tanaman. Kenyataan yang terlihat pada Tabel 1, nilai yang menjadi parameter rasio $\mathrm{C} / \mathrm{N}$ dan bahan organik justru terjadi peningkatan pada lama fermentasi 8 minggu dibandingkan lama fermentasi 2 minggu. Hal ini diduga berkaitan dalam pelaksanaan proses dekomposisi vase fermentasi terjadi kelemahan dalam mejaga kestabilan proses pembolak-balikan media dan menjaga suhu.

Secara locus, ada hubungan yang signifikan dari peran $\mathrm{N}$ total dalam proses rasio $\mathrm{C} / \mathrm{N}$ terhadap lamanya fementasi, hal ini dapat dilihat melalui uji $\mathrm{T}$ dan korelasi dari kedua perlakuan yang dicobakan. Sebaran data dari kelompok perlakuan dapat dilihat pada Tabel 3, sedangkan untuk melihat pola serta keeratan hubungan antara dua atau lebih variabel dari perlakuan pengecilan ukuran bahan dan lama fermentasi dapat dilihat pada Tabel 4.

Tabel 3. Analisis Uji T Sifat Kimia Kompos Kulit Ubi Akibat Pengecilan Ukuran Bahan dan Lama Fermentasi

\begin{tabular}{lrrr}
\hline \multicolumn{1}{c}{ Uji T } & $\begin{array}{c}\text { C organik } \\
(\%)\end{array}$ & \multicolumn{1}{c}{$\begin{array}{c}\mathrm{N} \text { total } \\
(\%)\end{array}$} & \multicolumn{1}{c}{$\mathrm{C} / \mathrm{N}$} \\
\hline $\begin{array}{l}\text { Pengecilan Ukuran } \\
\text { Bahan }\end{array}$ & & & \\
- Pencacah_manual & 34,7833 & 0,5917 & 60,0683 \\
- Penggilingan_mesin & 32,5467 & 0,5417 & 62,35 \\
\hline \multicolumn{1}{c}{$\quad$ Sig. 0,05) } & 0,117 & 0,447 & 0,75 \\
\hline Lama fermentasi & & & \\
- 4 minggu & 33,8217 & 0,4900 & 69,5683 \\
- 8 minggu & 33,5083 & 0,6433 & 52,85 \\
\hline \multicolumn{1}{c}{$\quad$ Sig. 0,05) } & 0,836 & $0,008^{* *}$ & $0,004^{* *}$ \\
\hline
\end{tabular}


Keterangan:

Ho = kedua sampel mempunyai varian yang sama ( $p>$ Sig. 0,05)

$\mathrm{Ha}=$ kedua sampel mempunyai varian yang berbeda $(\mathrm{p}<$ Sig. 0,05$)$

Tabel 4. Analisis Korelasi Sifat Kimia Kompos Kulit Ubi Kayu Akibat Pengecilan Ukuran Bahan dan Lama Fermentasi.

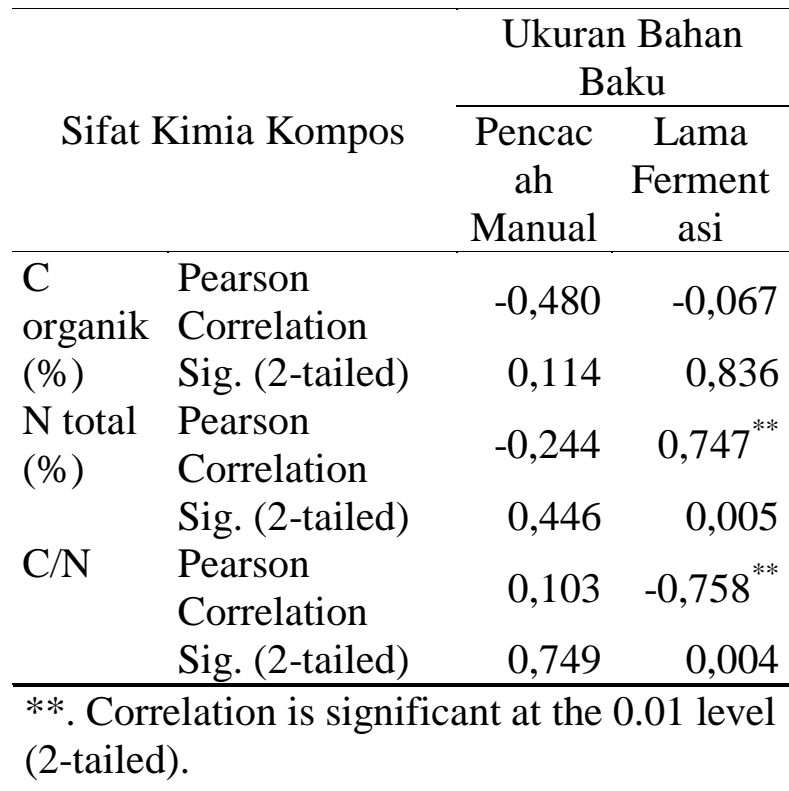

Tabel 3 terlihat ada perbedaan sebaran data pada kelompok lama fermentasi untuk $\mathrm{N}$ total dan sebaran $\mathrm{C} / \mathrm{N}$ demikian pula pada Tabel 4 terlihat pola arah hubungan yang positif pada $\mathrm{N}$ total dan arah hubungan negatif pada rasio $\mathrm{C} / \mathrm{N}$. Hal ini berkaitan erat dengan peran proses asimilasi $\mathrm{C}$ organik, dan dapat dibuktikan dari hasil analisis keragaman yang memperlihatkan adanya pengaruh yang signifikan atau sangat nyata terjadi pada kelompok lama fermentasi terhadap parameter sifat kimia kompos limbah kulit ubi kayu $\mathrm{N}$ total dan rasio $\mathrm{C} / \mathrm{N}$. Untuk lebih jelasnya dapat dilihat pada Tabel 5.

Tabel 5. Analisis anova keragaman sifat kimia kompos limbah kulit ubi kayu yang dicobakan

\begin{tabular}{lccc}
\hline \multicolumn{1}{c}{ Perlakuan } & $\begin{array}{c}\mathrm{C} \\
\text { organik } \\
(\%)\end{array}$ & $\begin{array}{c}\mathrm{N} \text { total } \\
(\%)\end{array}$ & $\begin{array}{c}\text { rasio } \\
\mathrm{C} / \mathrm{N}\end{array}$ \\
\hline $\begin{array}{l}\text { Pengecilan } \\
\text { Ukuran Bahan }\end{array}$ & & & \\
- Pencacah & & & \\
$\quad$ Manual & $32,75 \mathrm{tn}$ & $0,57 \mathrm{tn}$ & $58,68 \mathrm{tn}$ \\
- Penggilingan & $34,58 \mathrm{tn}$ & $0,56 \mathrm{tn}$ & $63,74 \mathrm{tn}$ \\
Lama & & & \\
Fermentasi & & & \\
- 4 minggu & $33,82 \mathrm{tn}$ & $0,49 \mathrm{a}$ & $69,57 \mathrm{a}$ \\
- 8 minggu & $33,51 \mathrm{tn}$ & $0,64 \mathrm{~b}$ & $52,85 \mathrm{~b}$ \\
\hline \multicolumn{1}{c}{ BNT 0,05} & 0,24 & 0,08 & 7,96 \\
\hline
\end{tabular}

Keterangan : $\mathrm{tn}=$ tidak nyata

C Organik merupakan salah satu komponen bahan organik yang menjadi penyusun sebagian besar bahan organik. COrganik penting untuk mikroorganisme tidak hanya sebagai unsur hara, tetapi juga sebagai pengkondisi sifat fisik tanah yang mempengaruhi karakteristik agregat dan air tanah juga berhubungan dengan aktivitas enzim tanah. Kandungan C-organik merupakan unsur bagi pupuk organik, karena tujuannya adalah untuk meningkatkan kandungan $\quad \mathrm{C}$-organik tanah yang pada umumnya sudah sangat rendah yaitu $2 \%$. Standar kandungan C menurut SNI kompos adalah 9,8\%-32\% (Wahyono, 2011).

Menurut Mirwan (2015) C-Organik merupakan indikator telah terjadinya proses dekomposisi dalam pengomposan dan kematangan kompos. Dalam proses dekomposisi, karbon digunakan sebagai sumber energi untuk menyusun bahan selulae sel-sel mikrobia dengan membebaskan $\mathrm{CO}_{2}$ dan bahan lain yang menguap. Bila jumlah C-Organik dalam tanah dapat diketahui maka kandungan bahan organik tanah juga dapat dihitung.

Sebagian besar nitrogen dalam tanah didapatkan dalam bentuk organik. Secara relatif hanya sebagian kecil dari nitrogen tanah terdapat dalam bentuk amonium dan nitrat yang merupakan bentuk nitrogen yang tersedia bagitanaman. 
Nilai rasio $\mathrm{C} / \mathrm{N}$ memperlihatkan proses perombakan bahan organik berlangsung dan telah terjadi proses mineralisasi unsur hara yang bermanfaat untuk kesuburan tanah. Rasio C/Nyang terlalu tinggi akan memperlambat proses pembusukan, sebaliknya jika terlalu rendah walaupun awalnya proses pembusukan berjalan cepat, tetapi akhirnya melambat karena kekurangan $C$ sebagai sumber energi bagi mikroorganisme (Pandebesie dan Rayuanti, 2012).

Selain itu kadar air juga sangat berpengaruh terhadap lamanya pengomposan/penguraian bahan-bahan organik dalam kompos (Widarti et al., 2015). Kadar air berkaitan dengan ketersediaan oksigen untuk aktivitas mikroorganisme aerobik, bila kadar air bahan berada pada kisaran 40-60,5\% maka mikroorganisme pengurai akan bekerja optimal (Sriharti dan Salim, 2002)

\section{KESIMPULAN}

1. Pengecilan ukuran bahan berpengaruh tidak nyata $\mathrm{C}$ organik, bahan organik dan rasio $\mathrm{C} / \mathrm{N}$. Lama fermentasi berpengaruh sangat nyata terhadap $\mathrm{N}$ total dan $\mathrm{C} / \mathrm{N}$, berpengaruh tidak nyata terhadap $\mathrm{C}$ organik.

2. Hasil analisis uji $\mathrm{T}$ terlihat ada perbedaan sebaran data pada lama fermentasi untuk $\mathrm{N}$ total dan sebaran $\mathrm{C} / \mathrm{N}$.

3. Ada hubungan yang signifikan dari peran $\mathrm{N}$ total dalam proses rasio $\mathrm{C} / \mathrm{N}$ terhadap lamanya fementasi dan terdapat pengaruh yang sangat nyata dari lama fermentasi terhadap $\mathrm{N}$ total dan rasio $\mathrm{C} / \mathrm{N}$.

\section{DAFTAR PUSTAKA}

Akanbi, et al., 2007. The Use of Compost Extract as Foliar Spray Nutrient Source and Botanical Insecticide in Telfairia occidentalis. World Journal of
Agriculture Sciences. 3(5), 642-652 dalam Hikmah, N. 2015. Pemanfaatan Ekstrak Kulit Singkong dan Air Cucian Beras Pada Pertumbuhan Tanaman Sirsak (Annona muricata L.). Artikel Publikasi. UNMUHA, Surakarta.

Djuarnani, N., Kristian dan Budi, S.S, 2005. Cara Cepat Membuat Kompos. Agromedia Pustaka. Jakarta.

Firmansyah, M.A. 2010. Teknik Pembuatan Kompos. Disampaikan pada Pelatihan Petani Plasma Kelapa Sawit di Kabupaten Sukamara, Kalimantan Tengah.

Yuliani, F dan F. Nugraheni. 2010. Pembuatan Pupuk Organik (Kompos) Dari Arang Ampas Tebu dan LimbahTernak. https://www.researchgate.net/publicatio $\underline{\mathrm{n} / 277257433}$ diakses pada 28 Agustus 2018.

Wahyono, 2011 Membuat Pupuk Organik Granul dan Aneka Limbah. Jakarta; Agromedia.

Mirwan, M. 2015. Optimalisasi Pengomposan Sampah Kebun dengan Variasi Aerasi dan Penambahan Kotoran Sapi sebagai Bioaktivator. Teknik Lingkungan. 4(6):61-66.

Nugroho, A. 2012. Pengaruh Bahan Organik Terhadap Sifat Biologi Tanah. Politeknik Negeri Lampung.

Pandebesie, E.S,. dan Rayuanti,D. 2012. Pengaruh penambahan sekam pada proses pengomposan sampah domestik. Jurnal Lingkungan Tropis 6(1): 31-40

Widarti, B.N., Wardhini, W.K,. Sarwono, E. 2015. Pengaruh rasio $\mathrm{C} / \mathrm{N}$ bahan baku 
Jurnal Sains Riset (JSR)

ISSN 2088-0952

pada pembuatan kompos dari kubis dan kulit pisang. Jurnal Integrasi Proses 5(2): 75-8.

Sriharti dan Salim, T. 2008. Pemanfaatan Limbah Pisang Untuk Pembuatan
Pupuk Kompos Menggunakan Kompos Rotary Drum. Prosiding Seminar Nasional Bidang Teknik Kimia dan Tekstil, Yogyakarta. 